\title{
МОДЕЛИРОВАНИЕ ФИНАНСОВОЙ ЭФФЕКТИВНОСТИ КОРПОРАЦИЙ ГОСУДАРСТВЕННО-ЧАСТНОГО ПАРТНЁРСТВА С ИСПОЛЬЗОВАНИЕМ ЗАРУБЕЖНОГО ОПЫТА
}

\author{
(C) 2019 Бакулина Анна Александровна \\ доктор экономических наук, доцент, профессор Департамента корпоративных финансов \\ и корпоративного управления, заместитель проректора по научной работе \\ Финансовый университет при Правительстве РФ, Россия, Москва \\ E-mail: abakulina@fa.ru
}

(c) 2019 Чараева Марина Викторовна

доктор экономических наук, доцент, профессор факультета управления

Южный федеральный университет, Россия, Ростов-на-Дону

E-mail: mvcharaeva@mail.ru

В современных экономических условиях вопросы повышения эффективности финансовохозяйственной деятельности российских корпораций имеют первостепенное значение. Однако, исследование финансовой эффективности корпораций, как правило, ограничивается использованием оценочных показателей и характеризуется отсутствием анализа использования возможностей государственно-частного партнёрства (ГЧП) на основе имеющегося зарубежного опыта. Цель статьи - сформулировать предложения по формированию модели оценки финансовой эффективности корпораций ГЧП с использованием зарубежного опыта. Результаты: разработка инструментария моделирования финансовой эффективности корпораций ГЧП на основе прогнозирования результатов финансово-хозяйственной деятельности

Ключевые слова: моделирование, корпорации государственно-частного партнёрства, финансовая эффективность, инструментарий, финансовое обеспечение, зарубежные модели, кредитоспособность, инфраструктура, прогнозирование

Внедрение системы государственно-частного партнёрства (ГЧП) даёт импульс для развития всей экономической системы на условиях эффективного взаимодействия и достижения высоких финансовых результатов. Использование многолетнего западного опыта позволит выстроить систему ГЧП на принципах и методах, которые являются основополагающими в деятельности банков в сфере инфраструктурного финансирования.

Следует рассмотреть методы и практики, которые посвящены минимизации рисков при кредитовании ГЧП. В первую очередь, целесообразно проанализировать опыт ПАО «Сбербанк России», который на данный момент при кредитовании предприятий ГЧП, в соответствии с разработанным «Коробочным» решением, имеет широкий перечень гарантий со стороны государства. Однако, такая практика имеет множество негативных эффектов таких, как: создание условий для недобросовестного ведения деятельности, а также включение третьей стороны (государства) в процесс кредитных отношений.
Кроме того, «Коробочное» решение несет в себе множество ограничений, касающихся финансового положения предприятия, опыта инфраструктурного менеджера, а также включает широкий перечень коммерческих условий.

В таблице 1 приведен перечень рекомендаций, составленный Всемирным банком. Каждый из методов предоставляет кредитору те или иные гарантии, а также возможность высокой комиссии в зависимости от степени риска, связанного с методом.

Особый интерес, с точки зрения повышения кредитоспособности инфраструктурной корпорации, представляет кредитная практика, широко распространенная в США, а именно: инфраструктурный аккредитив. В соответствии с данным методом кредитная организация гарантирует для корпорации ГЧП в случае нехватки денежных средств незамедлительное докредитование.

С точки зрения того, что Сбербанк, по сути, является посредником со стороны государства, в развитии сектора ГЧП интересно рассмотреть 


\section{Таблица 1. Методы повышения кредитоспособности в финансировании ГЧП рекомендуемые Всемирным банком}

\begin{tabular}{|c|c|c|}
\hline Инструмент & Описание & $\begin{array}{c}\text { Ключевая } \\
\text { особенность }\end{array}$ \\
\hline $\begin{array}{l}\text { Частичная кредитная } \\
\text { гарантия }\end{array}$ & $\begin{array}{l}\text { Эквивалентно структурированию «закрытой безопасности», как это } \\
\text { определено более широко в области структрированного финанси- } \\
\text { рования; это безотзывное обещание третьей стороны финансового } \\
\text { учреждения возместить кредитору / инвестору в случае технического } \\
\text { дефолта заемщика до определенной суммы (например, погашение } \\
\text { основной суммы и / или процентов) }\end{array}$ & $\begin{array}{l}\text { Типичная гарантия } \\
\text { составляет 30-50\% от } \\
\text { общей суммы обяза- } \\
\text { тельств }\end{array}$ \\
\hline Условия первой потери & $\begin{array}{l}\text { Обращайтесь к любому инструменту, предназначенному для защиты } \\
\text { инвесторов от потери капитала, которая в первую очередь подвергает- } \\
\text { ся непредсказуемым денежным потокам. Это защищает инвесторов от } \\
\text { заранее определенных первоначальных потерь. Часто структурируется } \\
\text { как частичная гарантия, описанная выше }\end{array}$ & $\begin{array}{l}\text { Это могут быть долго- } \\
\text { вые, долевые или про- } \\
\text { изводные инструменты, } \\
\text { такие как денежные } \\
\text { средства или гарантии }\end{array}$ \\
\hline Денежное обеспечение & $\begin{array}{l}\text { Наличные или эквивалентно ликвидные коммерческие бумаги, со- } \\
\text { бранные и хранящиеся на зарезервированном счете в пользу креди- } \\
\text { торов }\end{array}$ & \\
\hline $\begin{array}{l}\text { Инфраструктурный } \\
\text { аккредитив }\end{array}$ & $\begin{array}{l}\text { Письменное обязательство кредитного учреждения гарантировать } \\
\text { возмещение указанной денежной суммы в случае любой нехватки } \\
\text { финансов в проекте }\end{array}$ & $\begin{array}{l}\text { Ставка 10-15\%, покры- } \\
\text { тие по требованию }\end{array}$ \\
\hline $\begin{array}{l}\text { Страхование } \\
\text { политических рисков }\end{array}$ & \begin{tabular}{|l|} 
Покрытие частных кредиторов и инвесторов для определенных \\
рисков кредитования суверенных или суб-суверенных заемщиков. \\
По определению, Гарантия Политического Риска (ГПР) обязательно \\
должна включать частное участие в проекте. Некоторые покрываемые \\
риски влекут за собой неконвертируемость валюты, политические \\
форс-мажорные обстоятельства, такие как война, регуляторный риск и \\
выполнение обязательств по государственным платежам
\end{tabular} & $\begin{array}{l}\text { ГПР часто и выгодно } \\
\text { используются в проек- } \\
\text { тах зеленой энергии / } \\
\text { энергоэффективности }\end{array}$ \\
\hline $\begin{array}{l}\text { Синдицированный } \\
\text { кредит }\end{array}$ & $\begin{array}{l}\text { Процесс вовлечения нескольких разных кредиторов в предоставление } \\
\text { различных частей кредита. Синдицирование ссуды чаще всего проис- } \\
\text { ходит в ситуациях, когда заемщику требуется большая сумма капита- } \\
\text { ла, которая может быть слишком большой для одного кредитора или } \\
\text { выходит за рамки допустимых рисковых потерь }\end{array}$ & $\begin{array}{l}\text { Процентные ставки по } \\
\text { этому виду кредита мо- } \\
\text { гут быть фиксирован- } \\
\text { ными или плавающи- } \\
\text { ми, исходя из базовой } \\
\text { ставки }\end{array}$ \\
\hline Перестрахование & $\begin{array}{l}\text { Практика передачи страховщиками части портфелей рисков другим } \\
\text { сторонам по какой-либо форме соглашения для уменьшения вероят- } \\
\text { ности выплаты большого обязательства, вытекаюеего из страхового } \\
\text { возмещения. Перестрахование позволяет страховой компании при-- } \\
\text { нимать риски клиентов, которые были бы слишком велики для одного } \\
\text { страховщика }\end{array}$ & $\begin{array}{l}\text { Страховые выплаты, } \\
\text { обычно распределяется } \\
\text { между всеми вовле- } \\
\text { ченными сторонами } \\
\text { страхования }\end{array}$ \\
\hline $\begin{array}{l}\text { Резервные кредитные } \\
\text { линии }\end{array}$ & $\begin{array}{l}\text { Поручительный инструмент утверждаемый заранее для поддержжа- } \\
\text { ния основного долга путем предоставления денежных средств долж- } \\
\text { нику в случае серьезных внешних потрясений }\end{array}$ & $\begin{array}{l}\text { Могут быть стихийные } \\
\text { бедствия, политические } \\
\text { или экономические } \\
\text { потрясения }\end{array}$ \\
\hline $\begin{array}{l}\text { Промежуточное } \\
\text { финансирование }\end{array}$ & $\begin{array}{l}\text { Используется для первоначального финансирования, необходимого } \\
\text { для запуска проекта. Дальнейший анализ жизнеспособности проекта } \\
\text { указывает на слабые места, которые могут послужить поводом для } \\
\text { прекращения финансирования }\end{array}$ & $\begin{array}{l}\text { Может быть реали- } \\
\text { зовано посредством } \\
\text { капитальных грантов, } \\
\text { субординированных } \\
\text { займов или даже про- } \\
\text { центных субсидий для } \\
\text { решения конкретных } \\
\text { вопросов, влияющих } \\
\text { на жизнеспособность } \\
\text { проекта }\end{array}$ \\
\hline $\begin{array}{l}\text { Гарантия выполнения } \\
\text { обязательств }\end{array}$ & $\begin{array}{l}\text { Специализированный инструмент финансового поручительства, } \\
\text { применяемый финансовым учреждением (страховой компанией или } \\
\text { банком), чтобы гарантировать удовлетворительное завершение проек- } \\
\text { та и обеспечить достаточную ликвидность проекта для завершения } \\
\text { даже в случае форс мажорных обстоятельств }\end{array}$ & $\begin{array}{l}\text { Охватывает до } 100 \% \\
\text { стоимости проекта. } \\
\text { Широко используется } \\
\text { для обеспечения дого- } \\
\text { ворных обязательств } \\
\text { по проектированию и } \\
\text { строительству }\end{array}$ \\
\hline
\end{tabular}

Составлено автором по материалам Overview of LVC, PPP, and credit enchantment practices [Электронный pecypc] / The World Bank. Режим доступа: https://www.gfdrr.org/sites/default/files/program/Overview\%20of\%20LVC\%20PPP\%20Guarantee\%20 combined-compressed.pdf (Дата обращения: 10.05.2019) 
практику синдицированного кредита. К преимуществам метода можно отнести распределение рисков, возможность участия в проектах, для которых, в ином случае, рисковая сумма была бы превышена, возможность участия в наиболее крупных проектах ГЧП.

Использование данного метода кредитования поможет подключить различные коммерческие банки, в том числе и мелкие кредитные организации, тем самым, увеличив потенциальный объем инвестиций в инфраструктурное развитие страны (рис. 1).

Наибольшую долю в общем объеме инвестиций в ГЧП составляют проекты, для которых требуется инвестиций более 1 млрд. руб. Необходимо пояснить, что эта статистика включает только реализуемые проекты. Реальная потребность в инфраструктурных инвестициях на 2019 год составляет 4,8 трлн. руб. Суммарный объем инвестиций в данные проекты составляет 1,7 трлн. руб. (более 90\% от общего объема требуемых инвестиций в проекты ГЧП) (рис. 2).

Синергия ПАО Сбербанк и частных региональных банков позволит снизить издержки, связанные с изучением специфики местных инфраструктурных проектов, переложив эту обязанность на партнеров. Также на плечи региональных партнеров ляжет роль по контролю за исполнением инфраструктурного проекта. Региональные банки смогут войти в рынок инвестирования ГЧП, разделят риски с более крупным игроком, а также получат уже готовые инстру-
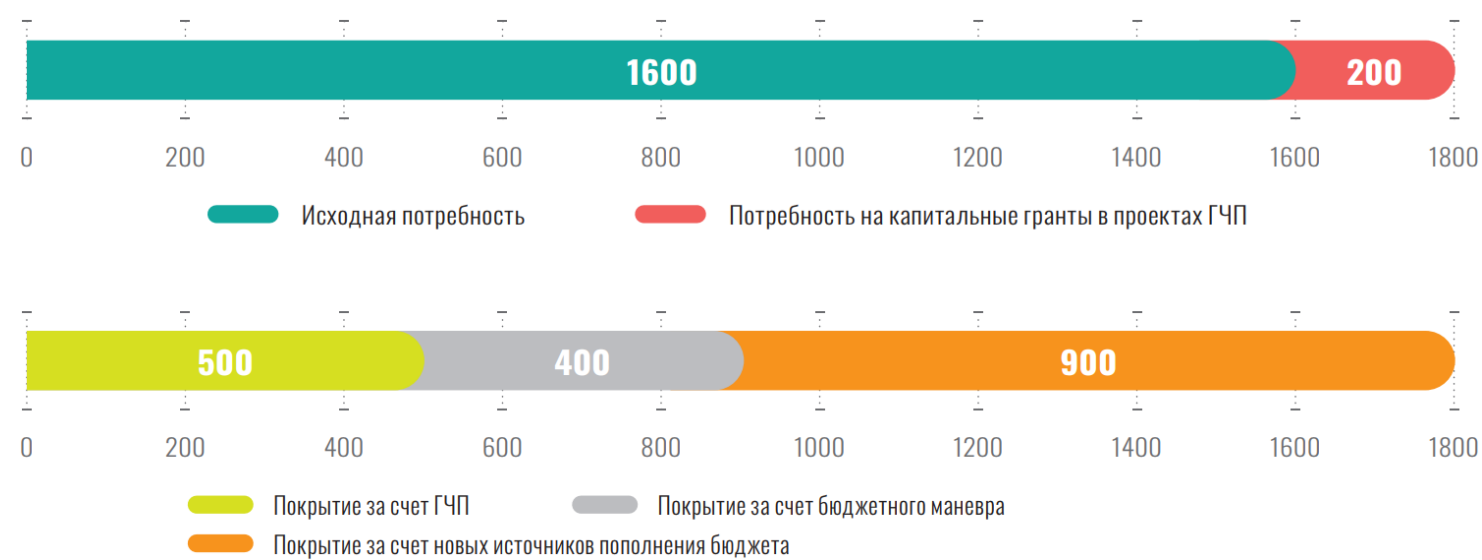

Рuc. 1. Потребность в инвестициях на инфраструктуру в 2019 году и возможные методы её покрытия, млрд. руб. [2]

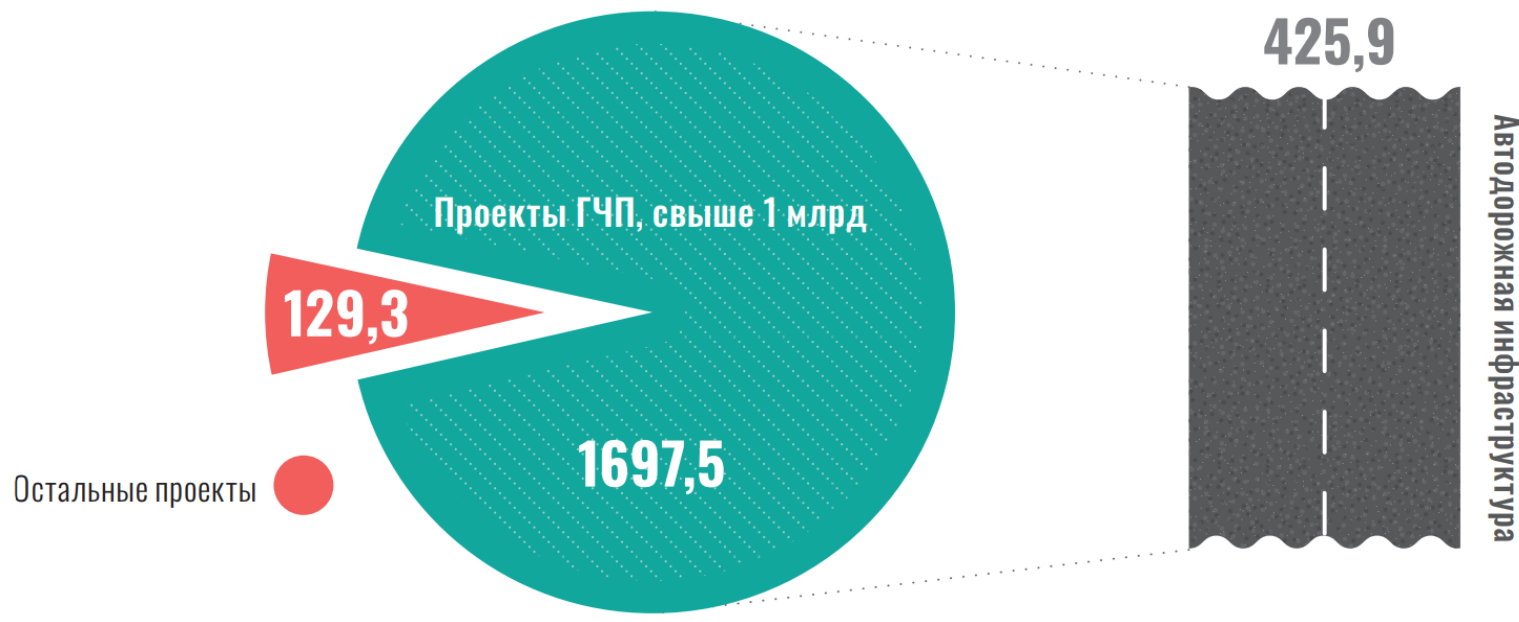

Рuc. 2. Распределение частных инвестиций в проектах ГЧП по категории свыше 1 млрд. руб., в млрд. руб. [2] 
менты для работы с проектами ГЧП.

При этом необходимо учитывать, что одна из ключевых проблем при инвестировании предприятий ГЧП и в России, и за рубежом, - это прогнозирование финансовых результатов проекта. Проекты ГЧП имеют длительный период жизни, в России для крупных проектов стоимостью инвестирования более 1 млрд. руб. это может быть 15 лет и более. Например, в ПАО Сбербанк в проекте «Коробочного» решения для кредитования инфраструктурных проектов заложена норма в 10-15 лет кредитования, но этот срок может быть и больше.

И если учесть, что проекты ГЧП требуют значительных финансовых вложений, а срок возврата инвестиций достигает десятка с лишним лет, становится очевидна необходимость в эффективном инструменте прогнозирования фи- нансовой эффективности проекта ГЧП.

Теоретическая модель финансовой эффективности проекта ГЧП разработана Осеи-Кей Робертом и Альбертом П.С. Чаном с использованием результатов исследований 2015 и 2017 г.г. На рисунке 3 показана концептуальная модель успеха проектов ГЧП.

За последние несколько десятков лет зарубежными практиками и теоретиками в области ГЧП были выявлены и проанализированы критические факторы эффективности (КФЭ) для проектов ГЧП в развивающихся странах [4]. Кроме того, были исследованы причинно-следственные связи между КФУ и критериями успеха для проектов ГЧП [5]. На основе этих исследований была построена модель для прогнозирования результатов ГЧП.

Концептуальная модель основана на тео-

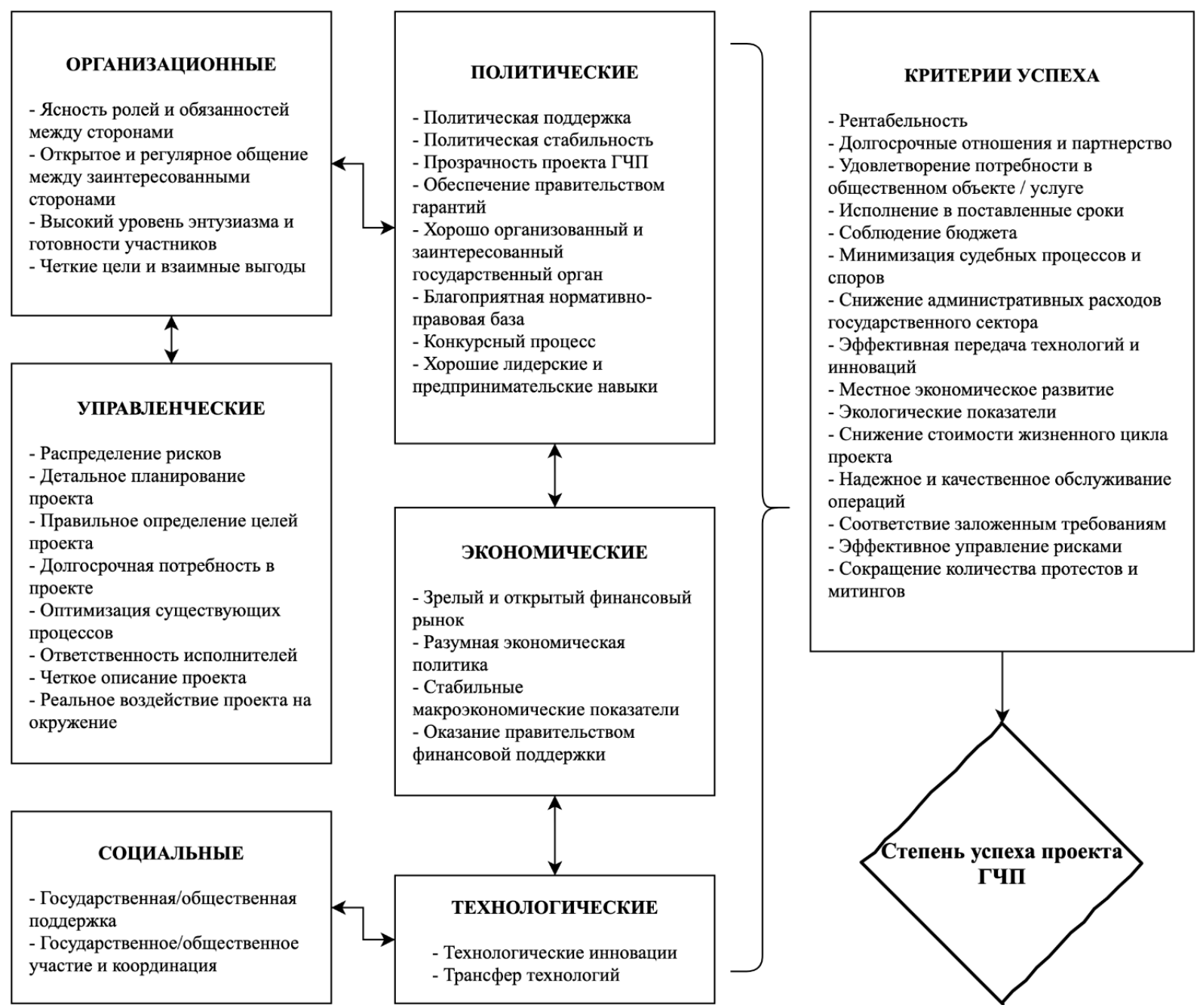

Рис. 3. Концептуальная модель эффективности ГЧП [3] 
ретическом допущении, предложенном Лимом К.С. и Мохамедом М.З. в исследовании 1999 года «Criteria of project success: An exploratory re-examination» о структуре эффективности проекта [6]. Лим и Мохамед предположили, что модель эффективности проекта состоит из двух ключевых частей: факторы и критерии. Факторы обозначают обстоятельства или условия, необходимые для достижения эффективности проекта. В то время как критерии указывают на набор принципов, по которым оценивается эффективность. Это подразумевает, что факторами и критериями являются КФЭ и критерии эффективности проекта, соответственно.

Таким образом, основой модели Роберта и Чана служат КФЭ в качестве первого компонента и критерии эффективности ГЧП - в качестве второго компонента. КФЭ для проектов ГЧП сгруппированы в шесть категорий. Условия, которые влияют на эффективность проектов ГЧП, происходят из внутренней и внешней среды. К шести категориям относятся политические, экономические, технологические, социальные, организационные и управленческие условия. По сути, каждое условие эффективности связано с другим. Например, политические условия оказывают непосредственное влияние как на экономические, так и на организационные условия эффективности проекта ГЧП и наоборот. Второй компонент модели (то есть критерии эффективности) состоит из 15 критериев (выявленных Робертом в исследовании 2017 года), которые основаны на удовлетворенности основных заинтересованных сторон проектов ГЧП (то есть государства, частного партнера и пользователей инфраструктурного проекта).

В целом, как показано в модели (рис. 3), шесть категорий условий в совокупности влияют на достижение критериев эффективности, которые затем определяют эффективность проекта ГЧП.

Для построения математической модели, которая прогнозирует эффективность проектов ГЧП в развивающихся странах, был использован метод множественного регрессионного анализа. В частности, метод многомерного анализа был использован для определения характера связей между переменными, то есть КФЭ и критериями эффективности проекта ГЧП. Множественный регрессионный анализ проводился с использованием формулы (1):

$$
Y_{p}=\alpha+b_{1} X_{i}+b_{2} X_{i i}+\cdots+b_{k} X_{k}+e_{i},(1)
$$

где $\alpha-$ точка пересечения / константа, $b_{1}$, $b_{2}, \ldots, b_{k}-$ коэффициенты регрессии, которые обозначают изменение оценки в $Y_{p}$ для единичного изменения $X_{i}, X_{i i} . ., X_{k}, e_{i}$ представляет прогнозную ошибку или остаток, $Y_{p}$ представляет собой зависимую переменную и $X_{i}, X_{i i}, \ldots, X_{k}$ являются независимыми переменными.

В исследовании Роберта и Чана регрессионная модель была подвергнута перекрестной проверке с использованием формулы (2):

Adjusted $R^{2}=1-\left[\left(\frac{n-1}{n-k-1}\right)\left(\frac{n-2}{n-k-2}\right)\left(\frac{n+1}{n}\right)\right]\left(1-R^{2}\right)$,

где $R^{2}-$ нескорректированное значение, $k-$ количество переменных регрессора в модели, а $n$ - количество наблюдений / выборка.

Следующим шагом построения модели было разделение 15 критериев успеха в 3 группы критериев успеха, которые затем использовали в модели индекса эффективности проекта (PSI), разработанной совместно с группой британских ученых, занятых развитием социального предпринимательства в Великобритании Foundation for Social Entrepreneurs (FSE).

Коэффициент фактора каждой критической группы критериев эффективности был заменен в уравнении PSI (формула (3)), и с помощью SPSS (программа для статистической обработки данных, один из лидеров рынка в области коммерческих статистических продуктов, предназначенных для проведения прикладных исследований в общественных науках) была вычислена зависимая переменная для регрессионного анализа.

Зависимая переменная (PSI) выражается с помощью формулы (3):

$$
P S I=(0.301 \times M P u У C)+(0.347 \times \text { ПРБЛ })+
$$

$(0.352 \times$ CTuTX $)$,

где $\mathrm{MPUУC} \mathrm{=} \mathrm{местное} \mathrm{развитие} \mathrm{и} \mathrm{уменьше-}$ ние споров, ПРБЛ = прибыль, CTUТХ = стоимость и технические характеристики.

Учитывая большое количество КФЭ, было важно уменьшить количество независимых переменных, чтобы минимизировать их влияние. С этой целью исследователями был проведен корреляционный анализ Пирсона для отбора независимых переменных, которые не имеют существенной корреляции с выходной переменной (PSI).

Пошаговая процедура отбора была исполь- 
Таблица 2. Результаты ступенчатой модели [3]

\begin{tabular}{|c|c|c|c|c|c|c|}
\hline Модель & $\mathrm{R} 2$ & Коррект. R2 & Стд. ошибка & Изм. R2 & $\begin{array}{c}\text { Значение } \\
\text { изм. F }\end{array}$ & $\begin{array}{c}\text { Критерий } \\
\text { Дарбина- } \\
\text { Уотсона }\end{array}$ \\
\hline 1 & 0.269 & 0.260 & 0.498 & 0.269 & 0.000 & \\
\hline 2 & 0.364 & 0.347 & 0.468 & 0.095 & 0.001 & \\
\hline 3 & 0.450 & 0.428 & 0.438 & 0.086 & 0.001 & 1.829 \\
\hline
\end{tabular}

зована для построения регрессионной модели. Это надежный инструмент, позволяющий выбирать переменную критерия. Процедура сильно усложняется, когда в регрессионном анализе участвует большое количество независимых переменных. Таким образом, учитывая, что количество независимых переменных (КФЭ) в этом исследовании довольно велико, Чан и Робертс решили использовать процедуру пошагового отбора в регрессионном анализе. Результаты поэтапной регрессии представлены в таблице 2 .

Исследование, проведенное Робертом и Чаном, привело их к построению эффективной модели прогнозирования с низким коэффициентом отклонения при перекрестной проверке. Коэффициенты, содержащиеся в формуле, выведенной по итогам исследования, могут быть переработаны с использованием данных более актуальных для конкретного региона.

$$
\begin{aligned}
& Y=-2.705+(0.353 \times M P u У C)+(0.312 \times \text { ПРБЛ })+ \\
& (0.307 \times \text { CТuTX }),
\end{aligned}
$$

Адаптация данного инструментария для вычисления с помощью вышеописанной модели степени финансовой эффективности корпорации ГЧП предполагает выполнение нескольких действий. Группа экспертов или участников проекта со стороны государственного и частного партнеров на ранних стадиях будет оценивать по пятибалльной шкале, с какой вероятностью могут быть достигнуты каждая из трех групп критериев формулы (3) в данном проекте (1 = вряд ли будет достигнуто, 3 = средняя вероятность и 5 = вероятно, будет достигнуто). Затем, среднее значение каждого из критериев эффективности подставляется в формулу (4), и рассчитывается степень эффективности в диапазоне от -2.705 до 2.155 , где значения выше 0 имеют положительную тенденцию достижения эффективности, при этом, 2.155 - это максимальная вероятность эффективности, а $-2,705$ - отсутствие эффективности.

Таким образом, мы получаем готовый для использования в российских экономических условиях инструмент моделирования финансовой эффективности корпорации ГЧП, который можно, благодаря подробному описанию его разработки, в случае необходимости, адаптировать под активно меняющиеся условия рынка инфраструктурного инвестирования. Основные преимущества использования данного инструментария в том, что нивелируется проблема прогнозирования финансовой эффективности корпораций ГЧП и становится возможной повсеместная интеграция финансовых механизмов ГЧП и привлечение новых, как небольших, так и крупных инвесторов в данную область экономических отношений.

\section{Библиографический список}

1. Overview of LVC, PPP, and credit enchantment practices [Электронный ресурс] / The World Bank. Режим доступа: https://www.gfdrr.org/sites/default/files/program/Overview\%20of\%20LVC\%20PPP\%20Guarantee\%20 combined-compressed.pdf (Дата обращения: 10.05.2019)

2. Проект национального доклада о привлечении частных инвестиций в развитие инфраструктуры и применении механизмов государственно-частного партнерства в Российской Федерации 2017-2018 [Электронный ресурс] офиц. портал / Центр развития ГЧП.- Режим доступа: http://pppcenter.ru/assets/ docs/22032019reiting.pdf (Дата обращения: 10.05.2019) 
3. Osei-Kyei R., Chan, A.P.C. Model for predicting the Success of Public-Private Partnership Infrastructure Projects in Developing Countries [Электронный ресурс] // Architectural Engineering and Design Management. 2019.Режим доступа: https://www.researchgate.net/publication/328757483_Model_for_predicting_the_Success_of_ Public-Private_Partnership_Infrastructure_Projects_in_Developing_Countries_A_Case_of_Ghana (Дата обращения: 14.05.2019)

4. Osei-Kyei, R., Chan, A.P.C. Review of studies on the critical success factors for public-private partnership (PPP) projects from 1990 to 2013 [Электронный ресурс] // International Journal of Project Management. 2015. - Peжим доступа: https://fenix.tecnico.ulisboa.pt/downloadFile/845043405444317/8\%20Eview\%20of\%20studies\%20 on\%20the\%20Critical\%20Success\%20Factors\%20for\%20PublicPrivate\%20Partnership\%20(PPP)\%20projects\%20 from\%201990\%20to\%202013.pdf (Дата обращения: 14.05.2019)

5. Osei-Kyei, R., Chan, A.P.C. Critical success criteria for public-private partnership projects: international experts' opinion [Электронный ресурс] // International Journal of Strategic Property Management. 2017.- Режим доступа: https://www.researchgate.net/publication/309159219_Critical_Success_Criteria_for_Public-Private_ Partnership_Projects_International_Experts’_Opinion (Дата обращения: 16.05.2019)

6. Lim C.S., Mohamed Z. Criteria of project success: An exploratory re-examination [Электронный ресурс] // International Journal of Project Management. 1999.- Режим доступа: https://www.researchgate.net/ publication/223092736_Criteria_of_project_success_An_exploratory_re-examination (Дата обращения: 15.05.2019) 